\title{
Effect of ephedrine in ketotic hypoglycaemia
}

\author{
J. M. COURT, M. E. DUNLOP, and T. J. C. BOULTON \\ From the Department of Paediatrics, University of Melbourne; and the Royal Children's Hospital, Parkville, \\ Victoria, Australia
}

Court, J. M., Dunlop, M. E., and Boulton, T. J. C. (1974). Archives of Disease in Childhood, 49, 63. Effect of ephedrine in ketotic hypoglycaemia. The effect of oral ephedrine administration on a child with ketotic hypoglycaemia who had not responded to dietary measures alone was studied. After ephedrine administration, the hypoglycaemia developing after ketogenic stress was less profound and was substantially delayed. The impaired glycaemic response to glucagon during hypoglycaemia, characteristic of ketotic hypoglycaemia, was not altered.

These observations are compatible with the proposition that ketotic hypoglycaemia is associated with impaired gluconeogenesis and they suggest that ephedrine may be a useful adjunct to therapy in this condition.

The clinical features and diagnostic criteria of ketotic hypoglycaemia have been well documented (Colle and Ulstrom, 1964), but the pathophysiology and an effective therapy are still not established.

Several workers reported a deficiency in epinephrine response to ketogenic stress in this condition (Koffler, Schubert, and Hug, 1971). On the basis cf this observation it has been suggested that ephedrine administration may prevent hypoglycaemia induced by fasting or ketosis (Koffler et $a l ., 1971)$. These authors reported, however, that they administered ephedrine to 3 patients without success. Rosenbloom and Tiwary (1972) reported that ephedrine sulphate improved tolerance to fasting and restored the glycaemic response to glucagon in the fasting state in 2 children they studied. In one of these children, hypoglycaemic episodes ceased during 22 months of ephedrine administration.

In view of these conflicting experiences, and the failure of dietary measures alone to prevent hypoglycaemia in some children, we have studied a child with ketotic hypoglycaemia both before and after ephedrine therapy. We wished to test the propositions that ephedrine may alter the hypoglycaemic response to ketotic stress in such children or, alternatively, that it may alter glucagon responsiveness in the presence of hypoglycaemia.

\section{Case report}

A girl aged 4 years was studied. She had been delivered by caesarean section at $35 \frac{1}{2}$ weeks' gestation

Received 23 July 1973. because of maternal pre-eclampsia. Birthweight was $1.4 \mathrm{~kg}$, and her condition was satisfactory until the 4th day of life when some twitching was observed. This ceased on administration of phenobarbitone. She developed normally until the age of 15 months when she had a grand mal convulsion. Another seizure occurred at 33 months associated with an upper respiratory infection, when she was found to have ketonuria and a plasma glucose value of $14 \mathrm{mg} / 100 \mathrm{ml}$. Intravenous dextrose promptly terminated the convulsion, and interval electroencephalogram was normal. Her mother was asked to test the urine regularly for the presence of ketones and was given dietary advice. Despite this, the child had recurrent seizures, all before breakfast and always associated with ketonuria. No improvement was noted with the administration of prednisolone and she was therefore referred for study.

Investigations included a 5-hour oral glucose tolerance test and a ketogenic stress test. She developed hypoglycaemia during this latter test, and was found to be unresponsive to intravenous glucagon while hypoglycaemic.

After 2 weeks at home on a normal diet she was readmitted to hospital and given ephedrine sulphate $5 \mathrm{mg}$ 6-hourly orally, continuing her normal diet. After 2 days a further ketogenic stress test was given under the same conditions as the previous test, but continuing ephedrine administration. Her response to intravenous glucagon was again tested when she became hypoglycaemic. On neither occasion while the child was hypoglycaemic did she convulse; she became drowsy but remained responsive throughout the test.

\section{Methods}

Oral glucose tolerance test. This was performed after 3 days of a normal high carbohydrate diet. After 
an overnight fast, glucose $1.7 \mathrm{~g} / \mathrm{kg}$ was given in a flavoured drink, and blood was taken for estimation of plasma glucose and insulin values at half-hourly intervals for 3 hours, and at 4 and 5 hours.

Ketogenic stress diet. A diet satisfying the child's calorie requirements, but with caloric proportions of $67 \%$ from fat, $16 \%$ from carbohydrate, and $17 \%$ from protein, was given until completion of the test. All urine specimens passed were tested for presence of ketones, and blood was collected for estimation of plasma glucose and insulin values approximately 6-hourly. When ketonuria was recorded, an intravenous catheter was inserted into a superficial arm vein and venous samples were taken 2-hourly. When hypoglycaemia was shown by Dextrostix (Ames), a glucagon stimulation test was performed.

Glucagon stimulation test. Glucagon $0.03 \mathrm{mg} / \mathrm{kg}$ was administered intravenously and blood was collected $15,30,45$, and 60 minutes after.

Laboratory estimations. Plasma glucose was estimated by a glucose oxidase method, plasma insulin by a radioimmunoassay of Herbert et al. (1965), and free fatty acids (FFA) by the colorimetric method of Novak (1965).

\section{Results}

The oral glucose tolerance test showed a fasting plasma glucose value of $70 \mathrm{mg} / 100 \mathrm{ml}$ rising to 140 $\mathrm{mg} / 100 \mathrm{ml}$ at 60 minutes. Values of $120,99,65$, and $57 \mathrm{mg} / 100 \mathrm{ml}$ were recorded at $2,3,4$, and 5 hours, respectively. Insulin response to oral glucose was low, with a fasting plasma insulin of 10 $\mu \mathrm{U} / \mathrm{ml}$ and peak response at 1 hour of $30 \mu \mathrm{U} / \mathrm{ml}$, and values of $30,10,4$, and $4 \mu \mathrm{U} / \mathrm{ml}$ at $2,3,4$, and 5 hours, respectively.

Results of the response to ketogenic stress, made before and during ephedrine administration, together with response to intravenous glucagon during hypoglycaemia, are set out in the Table. The Fig. shows the relation of onset of hypoglycaemia to development of ketonuria after starting the ketogenic diet. The results of the tests made during ephedrine administration show a delay in the development of hypoglycaemia after appearance of ketonuria, but no alteration in the lack of response to intravenous glucagon when hypoglycaemia eventually occurred. No alteration of insulin or FFA values was observed during ephedrine administration, and ephedrine was not associated with a delay in appearance of ketonuria.

\section{Discussion}

Our results do not support the report of Rosenbloom and Tiwary (1972) that ephedrine administration restores responsiveness to glucagon in ketotic hypoglycaemia. Their study, however, was inconclusive, as conditions under which the glucagon test was performed after treatment differed from those obtained before ephedrine administration. During the post-ephedrine test neither child was hypoglycaemic, and it was not recorded whether they had ketonuria. Glycaemic response to glucagon is only impaired in the ketotic hypoglycaemic state (Colle and Ulstrom, 1964) and is normal after short periods of fasting up to 12 hours (Pagliara et al., 1972).

TABLE

Ketogenic stress test and response to glucagon stimulation

\begin{tabular}{|c|c|c|c|c|c|c|c|c|c|}
\hline \multicolumn{5}{|c|}{ Before ephedrine administration } & \multicolumn{5}{|c|}{ During ephedrine administration } \\
\hline \multirow[b]{2}{*}{ Time* } & Urine & \multicolumn{3}{|c|}{ Plasma } & \multirow[b]{2}{*}{ Time* } & Urine & \multicolumn{3}{|c|}{ Plasma } \\
\hline & Ketonest & $\begin{array}{c}\text { Glucose } \\
(\mathrm{mg} / 100 \mathrm{ml})\end{array}$ & $\begin{array}{c}\text { Insulin } \\
(\mu \mathrm{U} / \mathrm{ml})\end{array}$ & $\begin{array}{c}\text { FFA } \\
(\mu \mathrm{Eq} / \mathrm{l} .)\end{array}$ & & Ketonest & $\begin{array}{c}\text { Glucose } \\
(\mathrm{mg} / 100 \mathrm{ml})\end{array}$ & $\underset{(\mu \mathrm{U} / \mathrm{ml})}{\text { Insulin }}$ & $\begin{array}{c}\text { FFA } \\
(\mu \text { Eq } / 1 .)\end{array}$ \\
\hline $\begin{array}{l}0 \\
7 \\
14 \\
17 \\
23 \\
26 \\
26 \frac{8}{4} \\
27 \\
27 t \\
27 \frac{1}{2}\end{array}$ & $\begin{array}{c}\text { Neg } \\
\text { Neg } \\
+\end{array}$ & $\begin{array}{rr}76 & \\
63 & \\
47 & \\
17 & \\
3 & \\
& \text { Glu } \\
9 & \\
8 & \\
14 & \end{array}$ & $\begin{array}{c}\overline{41} \\
34 \\
16 \\
6 \\
- \\
5 \text { stimul } \\
9 \\
<4 \\
<4\end{array}$ & $\begin{array}{l}- \\
\bar{Z} \\
2200 \\
2240 \\
- \\
- \\
-\end{array}$ & $\begin{array}{r}0 \\
7 \\
12 \\
18 \\
21 \\
23 \\
25 \\
27 \\
35 \\
37\end{array}$ & $\begin{array}{l}+ \\
+ \\
+ \\
+\end{array}$ & $\begin{array}{l}80 \\
80 \\
86 \\
93 \\
86 \\
73 \\
74 \\
73 \\
44 \\
29\end{array}$ & $\begin{array}{r}21 \\
16 \\
4 \\
17 \\
4 \\
6 \\
10 \\
7 \\
-8\end{array}$ & $\begin{array}{l}- \\
\bar{Z} \\
\overline{1964} \\
\bar{Z} \\
2240 \\
\bar{Z} \\
-\end{array}$ \\
\hline 28 & & 17 & 10 & 一 & $\begin{array}{l}37 t \\
37 \frac{1}{2} \\
37 \frac{8}{4} \\
38 \\
34 t\end{array}$ & & $\begin{array}{ll} & \mathrm{Gl} \\
35 & \\
29 & \\
34 & \\
26 & \end{array}$ & $\begin{array}{c}\text { yon stimul } \\
9 \\
4 \\
4 \\
<3\end{array}$ & $\bar{Z}$ \\
\hline
\end{tabular}

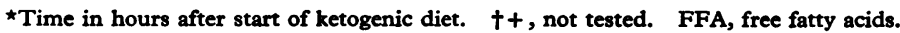




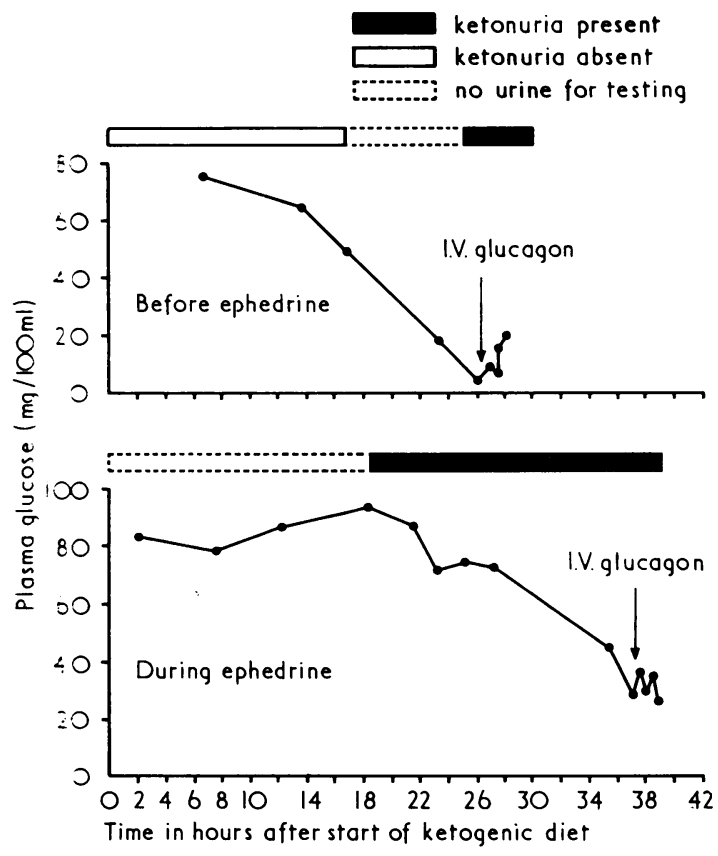

FIG.-Effect of ephedrine administration in delaying onset of hypoglycaemia after ketogenic stress.

In our study, ephedrine administration did, however, appear to influence post-ketotic hypoglycaemia, both in degree and in the time it took to develop. The mechanism whereby ephedrine administration may favourably influence glucose homoeostasis in this condition remains speculative. Our results are compatible with the proposition that children with ketotic hypoglycaemia have impaired gluconeogenesis (Colle and Ulstrom, 1964), and Pagliara et al. (1972) have suggested that this may be due to diminished availability of amino acid substrates. They showed low levels of plasma alanine in children with ketotic hypoglycaemia. Ephedrine is a sympathomimetic amine with an epinephrine-like effect, and leads also to release of norepinephrine from adrenergic nerve endings (Chidsey, Harrison, and Braunwald, 1962). Epinephrine leads to increased glycogenolysis by activation of hepatic phosphorylase (Sutherland and Rall, 1960) and decreased peripheral utilization of glucose (Drury and Wick, 1958, Dickman, Wiest, and Eik-Nes, 1958).

Thus, while adequate glycogen stores exist, ephedrine may help maintain glucose homoeostasis under conditions of stress. When glycogen stores are depleted in the fasting ketotic state and glucose levels are not sustained by gluconeogenesis, ephedrine cannot be expected to prevent hypoglycaemia nor restore responsiveness to glucagon.

Levels of plasma FFA and insulin did not appear to be influenced by ephedrine administration. We recorded relatively low values of plasma insulin as reported by Senior and Loridan (1969).

Dietary advice to the mother and instruction to give additional sugar when her child has ketonuria remain the basis for management of ketotic hypoglycaemia. If this fails to prevent episodes of hypoglycaemia however, oral ephedrine administration may have therapeutic value.

\section{REFERENCES}

Chidsey, C. A., Harrison, D. C., and Braunwald, E. (1962). Release of norepinephrine from the heart by vasoactive amines. Proceedings of the Society for Experimental Biology and Medicine $109,488$.

Colle, E., and Ulstrom, R. A. (1964). Ketotic hypoglycemia. fournal of Pediatrics, 64, 632.

Dickman, S. R., Wiest, W. G., and Eik-Nes, K. (1958). Effects of epinephrine on metabolism of glucose of normal dogs. American fournal of Physiology, 194, 327.

Drury, D. R., and Wick, A. N. (1958). Epinephrine and carbohydrate metabolism. American fournal of Physiology, 194, 465

Herbert, V., Lau, K., Gottleib, C. W., and Bleicher, S. J. (1965) Coated charcoal immunoassay of insulin. Fournal of Clinical Endocrinology, 25, 1375.

Koffler, H., Schubert, W. K., and Hug, G. (1971). Sporadic hypoglycemia: abnormal epinephrine response to the ketogenic diet or to insulin. Fournal of Pediatrics, 78, 448.

Novak, M. (1965). Colorimetric ultramicro-method for the determination of free fatty acids. Fournal of Lipid Research, 6 , 431.

Pagliara, A. S., Karl, I. E., De Vivo, D. C., Feigin, R. D., and Kipnis D. M. (1972). Hypoalaninemia: a concomitant of ketotic hypoglycemia. Fournal of Clinical Investigation, 51, 1440.

Rosenbloom, A. L., and Tiwary, C. M. (1972). Ketotic (idiopathic glucagon unresponsive) hypoglycaemia : catecholamine excretion and effects of ephedrine therapy. Archives of Disease in Childhood, 47, 924.

Senior, B., and Loridan, L. (1969). Gluconeogenesis and insulin in the ketotic variety of childhood hypoglycemia and in control children. Fournal of Pediatrics, 74, 529.

Sutherland, E. W., and Rall, T. W. (1960). The relation of adenosine- $3^{\prime}, 5^{\prime}$-phosphate and phosphorylase to the actions of catecholamines and otter hormones. Pharmacological Reviews, 12, 265.

Correspondence to Dr. J. M. Court, Department of Paediatrics, Royal Children's Hospital, Parkville, Victoria 3052, Australia. 